ARTÍCULOS DE REFLEXIÓN
TENDENCIAS

Revista de la Facultad de Ciencias Económicas y Administrativas. Universidad de Nariño

Vol. XVI. No. 1 - 1er. Semestre 2015, Enero-Junio - Páginas 99-124

\title{
MODERNIDAD, DESARROLLO Y EDUCACIÓN: DE LAS CAUSAS DE LO CIVILIZATORIO HACIA LA CRISIS CIVILIZATORIA
}

\author{
Por: Víctor Javier Erazo Pantoja ${ }^{1}$ - Luis Miguel Erazo Pantoja ${ }^{2}$
}

\section{RESUMEN}

Sobre la base de los estudios poscoloniales, el artículo hace una reflexión acerca de las principales características constitutivas a la modernidad, como resultado de un proceso que configuró las cualidades del moderno sistema mundial y, al margen de estas, las especificidades del desarrollo como componente fundamental de sus condiciones contemporáneas. Analiza cómo dichas características, han conllevado a la generación de una crisis civilizatoria sin precedentes; crisis que la humanidad afronta como dinámica del agotamiento del sistema y crisis que ha permeado la educación, convirtiéndola en elemento establecido al servicio del modelo de desarrollo capitalista. El desarrollo, es también objeto de indagación, en la medida en que se hace un aporte desde la descripción de algunos procesos de transformación del pensamiento, a partir de la complejidad, hacia y para la creación de nuevos modelos de desarrollo: racionalidad alternativa y modo de vida alternativo, como elementos que pueden contribuir con la transformación de la educación. Se encontró en el proceso, que es en la educación, en conjunción con la transformación del pensamiento, donde están las bases para la superación de la crisis civilizatoria. Superación posible, a través del cambio de las prácticas educativas, entre ellas, las relaciones sociales (de alteridad) de sus actores.

Palabras clave: Crisis civilizatoria, Modernidad, Moderno sistema mundial, desarrollo, modo de vida alternativo, educación.

Clasificación JEL: 121; O10.

1. Docente adscrito al departamento de Ciencias Sociales de la Universidad de Nariño; miembro del grupo de investigación Edu-Multiverso; vijaep@gmail.com.

2. Sociólogo, Universidad de Nariño; miembro del grupo de investigación Edu-Multiverso; leluigui@ gmail.com.

Artículo recibido: 1 de abril de 2014.

Aprobación definitiva: 22 de noviembre de 2014. 


\title{
MODERNITY, DEVELOPMENT AND EDUCATION: CAUSES FROM CIVILIZING TO THE CIVILIZATION CRISIS
}

\author{
By: Víctor Javier Erazo Pantoja - Luis Miguel Erazo Pantoja
}

\begin{abstract}
On the basis of postcolonial studies, the article is to think about the main constituent of modernity, as a result of a process that shaped the qualities of the modern world system and, apart from these, the specific component of development as key features their contemporary conditions. Analyzes how these characteristics have led to the generation of an unprecedented crisis of civilization; crisis facing humanity as a dynamic system and depletion crisis has permeated education, making the service element established model of capitalist development. The development is also under investigation, to the extent that a contribution from the description of some of the thought processes of transformation, from the complexity, to and for the creation of new development models is: rationality and alternative mode alternative livelihood, as elements that can contribute to the transformation of education. It was found that in education, in conjunction with the transformation of thought, overcoming the crisis of civilization is. Possible improvement, through change of educational practices, including social relationships (otherness) of education stakeholders.
\end{abstract}

Key words: civilization crisis, modernity, worldwide modern system, development, alternative way of living, education.

Classification JEL: 121; 010. 


\section{Introducción}

En un texto publicado en el año 2011, la filósofa argentina Isabel Rauber, daba a conocer algunas de las características de aquello que ella denominó como "crisis sistémica” o "crisis civilizatoria” (Rauber, 2011:16); la misma, en palabras de Julián Sabogal (2012: 29), se traduciría como "la crisis sin precedentes”. Básicamente, se trataba de un esfuerzo por comprender las consecuencias sistémicas globales generadas por el modo capitalista de producción, como marco del sistema-mundo capitalista y sus diferentes operaciones; a decir por ejemplo del proceso civilizatorio generado por la modernidad y al interior de esta, la emergente necesidad occidental de conducir a sus sociedades por la senda del progreso y el desarrollo, como las metas, conditio sine qua non, occidente produciría su prosperidad, emancipación, libertad, riqueza y felicidad.

Rauber, enfatiza que lejos de generar tales cometidos para la totalidad de las sociedades atravesadas y enclaustradas al interior del seno del sistema-mundo, hoy nos encontramos abocados ante una situación crítica y caótica que amenaza la estabilidad de la vida misma en la tierra, debido a las condiciones del capitalismo como sistema, que extirpa irracionalmente todos los medios y recursos que favorecen la existencia de la vida en el planeta, como resultado de las lógicas neoliberales del mercado, del consumo y la acumulación de capital.

Se trata de un agotamiento civilizatorio integral y multidimensional: (...) modo de producción, reproducción, distribución (intercambio), apropiación y acumulación económica, cultural, social y política que se ha desarrollado a tal punto que hoy evidencia descarnadamente la irracionalidad creciente contenida en su inicial racionalidad, irracionalidad que se expresa nítidamente en su irrefrenable destructividad de vida, un modo de no-vida que cínicamente pretenden sostener y defender, disfrazándolo como un estado “natural”... (Rauber, 2011:16).

Agotamiento, respecto del cual han jugado un papel esencial la modernidad y el desarrollo; la primera como aquel proceso que determinó las circunstancias por las cuales se configuró el sistema-mundo capitalista y, el segundo, como mecanismo de y para la prolongación y ampliación de dicho sistema que, como producto de la modernidad, ha protagonizado un papel imprescindible para la economía, estableciendo los lineamientos y senderos que debían transitar las sociedades para asegurar un modo de vida considerado próspero y solventado en la acumulación de riqueza, el mantenimiento del mercado, la explotación de recursos, el deterioro de los ecosistemas y, por supuesto, la diferenciación de la humanidad, entre los habitantes del "centro y la periferia", o peor aún del "primer y tercer mundo".

Ante esto, pensadores contemporáneos como: Dussel (2000), Quijano (2000), Castro-Gómez (2005), Quijano Valencia (2006), Castro-Gómez \& Grosfoguel (2007), Morín (2007), Sabogal (2009, 2010, 2012, 2013), Marañon-Pimentel (2014), además de la misma Rauber (2011), han establecido que como opción a estas eventualidades, la humanidad debe enfrentarse a la urgente obligación de gestar nuevas formas o modos de vida como alternativas al "desarrollo", que permitan superar la "crisis civilizatoria”. Se trata de un proceso que inalienablemente debe comenzar con la 
descolonización del pensamiento; una marcha anticolonial, descolonial o si se quiere decolonial ${ }^{3}$, como aquel "proyecto de sociedad donde se posicione la liberación sobre la dominación y la explotación humana y la recuperación del vínculo relacional con la naturaleza como intereses históricos" (Marañon-Pimentel, 2014:10).

Es en este contexto, a partir de donde se han construido nuevas conceptualizaciones alrededor del desarrollo, como es el caso de la "racionalidad alternativa" (Marañon-Pimentel, 2014), el "desarrollo alternativo", el "desarrollo humano multidimensional" (Sabogal, 2010) o el "modo de vida alternativo" (Sabogal, 2013); conceptualizaciones que sin ser distantes de la necesidad por apelar a una transformación de las maneras de generar pensamiento y conocimiento diferente, capaz de hacerle frente a la crisis civilizatoria, están de acuerdo con la emergente obligación que tal proceso requiere, si de transformar la educación o mejor, generar una alternativa del "desarrollo" de y para la educación se trata.

El presente trabajo, busca en ese sentido, dar respuestas a los siguientes cuestionamientos: ¿qué podría comprenderse por modernidad y cómo al interior de esta se gestó el moderno sistema mundial (sistema-mundo capitalista) o capitalismocolonial-moderno?, ¿qué es el desarrollo, en términos de las características del moderno sistema mundial? ¿Qué podría comprenderse como posible alternativa al desarrollo y, en ello, cómo la educación puede favorecerse en el marco de dichas propuestas?

\section{El proyecto de la modernidad como emergencia del capitalismo mundial}

La modernidad es un acontecimiento mundial-global cuya esencia es la colonialidad, cuya contraparte y emergencia hacia la construcción de una racionalidad alternativa es la descolonidalidad (Marañon-Pimentel, 2014:21) o la crítica anticolonial y, cuyo producto, es el afianzamiento del "moderno sistema mundial" (Wa-

3. En la academia latinoamericana y en el marco de los estudios poscoloniales existen ciertos debates alrededor de las categorías decolonial y descolonial. Desde el grupo denominado por Arturo Escobar como: "Proyecto latino/latinoamericano modernidad/colonialidad", integrado entre otros por: Santiago Castro-Gómez, Ramón Grosfoguel, Arturo Escobar, Walter Mignolo, Anibal Quijano, Edgardo Lander entre otros, se utiliza la categoría decolonial, trabajada alrededor del ejercicio epistemológico llamado el giro decolonial, a partir del cual se aclara que "Asistimos, más bien, a una transición del colonialismo moderno a la colonialidad global, proceso que ciertamente ha transformado las formas de dominación desplegadas por la modernidad, pero no la estructura de las relaciones centro-periferia a escala mundial". Por eso, prefieren utilizar la categoría decolonización más que descolonización, puesto que tal proceso no significó como lo manifiestan algunos discursos, el fin de las administraciones coloniales y la formación de los Estados-nación en la periferia; hecho que constataría que vivimos ahora en un mundo descolonizado y poscolonial. (Castro-Gómez \& Grosfoguel, 2007:13) Así, desde el pensamiento decolonial se argumenta que no vivimos en un mundo descolonizado o simplemente poscolonial, si no que dada la trascendencia mundial de la colonialidad del poder y del saber, existe una obligación latinoamericana de gestar un renovado proceso de descolonización - este sería la decolonización- que implique verdadera liberación. Al respecto y dados los propósitos de este texto, sin privilegiar una u otra categoría, se usará la noción de descolonización propuesta por Marañon-Pimentel, asimilándola como parte de una crítica anticolonial y si se quiere dada la convergencia de sus intenciones -dejando de lado el debate semántico y gramatical de los conceptos- decolonial, que privilegia una transformación del pensamiento y en ello de las relaciones sociedad-naturaleza como uno de los aspectos centrales en el ejercicio de superar la crisis civilizatoria. 
llerstein, 2005: 489), también denominado como "capitalismo-colonial-moderno"4 Enrique Dussel, da cuenta de las características de tal fenómeno:

La Modernidad es (...) una "salida" de la inmadurez por un esfuerzo de la razón como proceso crítico, que abre a la humanidad a un nuevo desarrollo del ser humano (...) la "Modernidad", en un sentido mundial, (...) consistiría en definir como determinación fundamental del mundo moderno el hecho de ser (sus Estados, ejércitos, economía, filosofía, etc.) "centro" de la Historia Mundial (2000: 45-46).

No es un proyecto producido exclusivamente por Europa. Es un hecho mundial de larga duración, cuya génesis data de los tiempos que parten del 12 de octubre de 1492. Por eso, la modernidad no se debe solamente al esfuerzo europeo por la construcción y búsqueda de su propio desarrollo y progreso; es resultado de la concatenación de acontecimientos mundiales, resultado del colonialismo y la colonialidad del saber y del poder; elementos que coadyuvaron al desarrollo global del capitalismo.

El colonialismo es y fue aquel proceso, a través del cual los países europeos desde el siglo XVI, comenzaron a constituir, -dominando administrativa y políticamente- a otros territorios no europeos (América, Asia, África y Oceanía) mediante la imagen europea; en todo caso respecto de la Totalidad ontológica y epistemológica occidental: "eurocentrismo con sus pretensiones de universalidad y de único conocimiento válido, [que] legitima el poder del capital y naturaliza los procesos sociales" (Marañon-Pimentel, 2014: 9).

Su operación consistió en el traslado a estos países, de la organización económica, política, administrativa, social y cultural de los Estados europeos, a raíz del desmantelamiento administrativo, económico, político, social y cultural, de las estructuras no europeas, de las futuras sociedades colonizadas. Tal situación, trajo como resultado la colonialidad, como elemento constitutivo de la modernidad y producto del establecimiento irreversible de las colonias en el Nuevo Mundo, sobre todo, a partir de la formación, afianzamiento y fijación "del circuito comercial del atlántico" (Mignolo, 2000: 58).

La colonialidad, empezaría a generar y definir las características de la modernidad. Definida como la plataforma discursiva-epistémica mediante la cual se valieron las potencias europeas para perpetrar sus propósitos, la colonialidad establecería los componentes materiales y cognitivos que le concedieron al europeo su imagen empoderada y justificada de civilizador y colonizador. Además de conferirle al colonizado su posición, imagen y cuerpo de bárbaro, indio y mestizo incivilizado. Circunstancias que determinarían, la ulterior modernización, civilización y mundialización de las sociedades latinoamericanas; esto es, el proceso civilizatorio.

4. Término construido por Aníbal Quijano que da cuenta del capitalismo dentro de una sola significación, con relación a aquello que ha sido y es, desde las maneras como ha operado y opera en nuestros contextos y el contexto mundial; en palabras de Quijano: el "capitalismo mundial, fue, desde su partida, colonial-moderno y eurocentrado”. (Quijano, 2000: 208). 
Tal colonialidad, a partir de aquella relación inmanente, continua y dinámica entre el saber y el poder, contribuyó a la generación de una cadena de acontecimientos trascendentales en el tiempo y la historia. Acontecimientos que instauraron una serie de órdenes y mecanismos que aún actualmente, no dejan de esparcir y poner en práctica sus intenciones colonizadoras, ahora poscoloniales y en los bordes de las emergentes dinámicas descoloniales.

¿En qué medida y a raíz de qué proceso, la colonialidad del saber y del poder, contribuyeron histórica y socioculturalmente, al afán de la modernidad por generar las cualidades de la sociedad actual, particularmente de la sociedad latinoamericana?

Si se entiende a la colonialidad del saber, como la subvaloración epistémica y discursiva implantada por occidente -el conquistador, colonizador, europeo y posteriormente el norteamericano y capitalista- sobre el conocimiento del otro colonizado -en este caso indios y negros ignorantes, campesinos iletrados y mestizos analfabetas, cuyas formas de conocimiento son desde estas configuraciones arcaicas, míticas, incivilizadas y supersticiosas- y, si se concibe a la colonialidad del poder, como aquel mecanismo epistémico concreto para la dominación y el control de las subjetividades, "a través de la cual fueron sometidas las poblaciones nativas de América a partir de 1492" (Castro-Gómez, 2005: 58), se puede sostener que la modernidad exhibe un proceso que implica e implicó, la estructuración de unos "imaginarios latinoamericanos" (Mignolo, 2002: 21-23); esto es, la puesta en práctica de unas peculiaridades discursivas que para Mignolo, comprenderían un reordenamiento geopolítico (del conocimiento) mundial, junto a la constante degradación y establecimiento de la actual Latinoamérica.

El imaginario del periodo colonial, -primero de ellos y único en su géneroenmarcado por el meta-relato cristiano (siglo XVI al XVIII), le proporcionaría al colonizador europeo aquellas herramientas, que justificando no sólo su dominación, posibilitarían una colonización basada en los preceptos de la evangelización cristiana. La misma, procuraría exterminar los sistemas cosmológicos y ontológicoreligiosos de las sociedades encontradas en el Nuevo Mundo.

Aspectos que supondrían la entrada victoriosa para el mundo conquistado, de las prácticas de colonialidad. Una de estas prácticas fue -y si se quiere es- la clasificación racial ${ }^{5}$ de la población; situación que conllevó a la academia española de la época, a cuestionarse acerca de si los indios conquistados eran hijos de Dios o si tenían alma. A su vez, tales sucesos viabilizaron otras prácticas: la organización de mecanismos para la explotación de recursos y productos, trabajo y productos y, sexo y productos. Todo, mediante la institucionalización de dispositivos como la encomienda, la mita y el resguardo: convergencias entre la colonialidad del saber

5. “Con el tiempo, los colonizadores codificaron como color" (indios, negros, mestizos, en principio. Después con la expansión europea al viejo mundo y la creación del imaginario "Oriente" aceitunados y amarillos) "los rasgos fenotípicos de los colonizados y lo asumieron como la característica emblemática de la categoría racial (...) En consecuencia, los dominantes se llamaron a sí mismos blancos". (Quijano, 2000:203). 
y la colonialidad del poder; la primera instaurada desde el sujeto, la segunda desde la consolidación de funciones sociales.

Más adelante, como segundo momento y redefinición de los imaginarios latinoamericanos, aparecería el del "periodo nacional". Este, se concretaría con una paulatina degradación de las moribundas colonias, las cuales significaban para gran parte de los franceses ilustrados y para pensadores como Hegel ${ }^{6}$, aquel obstáculo para su propia modernización, desde el afán de una edificación obligatoria de Estados-nacionales progresistas. Tal imaginario, determinado entre los comienzos del siglo XVIII y 1898, se caracterizaría por una continua lucha contra el imaginario anterior desde el ideal revolucionario y laico de la burguesía ilustrada en Francia.

Situaciones perceptibles, solamente dados los sucesos de las guerras de independencia en contra de España, las cuales dieron por resultado, la conformación de los Estados-nacionales latinoamericanos, pensados e ideológicamente planeados, por la sociedad criolla de la época, influida por el pensamiento ilustrado-burgués (colonialidad del poder y saber); pensamiento que definiría las estructuras de un nuevo modelo de sujeto: un otro colonizado, en apariencia descolonizado.

Finalmente, tendría su entrada triunfal, el vigente y permanente "imaginario postnacional", con la tercera pero no la última degradación para Latinoamérica, ocurrida desde 1898, cuando sus países establecerían relaciones con Estados Unidos (erigida entonces como la nueva potencia mundial).

Estos acontecimientos, instituyeron desde ese momento, la configuración definitiva del actual sujeto latinoamericano: hispanohablante, subalterno y excluido, quien afronta y vive en una sociedad globalizada dependiente de economías externas como la norteamericana; y quien está al margen del proceder del capital en su orden transnacional a través del neoliberalismo, que amenaza con arrebatar las inmanencias culturales de algunas de las sociedades latinoamericanas, que por fortuna persistieron a las dinámicas arriba descritas.

Wallerstein (1995), relata las características que en estos escenarios de modernización y globalización modernos, deben afrontar este tipo de sujetos: una organización del sistema-mundo capitalista a partir de las relaciones entre "el centro y la periferia” (Wallerstein, 1995:144); relaciones que deviniendo históricas, encuentran su génesis en la inserción de América al sistema-mundo en 1492, se concretan mediante el proceso de revolución industrial (finales del siglo XVIII y comienzos del XIX) y se afirman mediante el fenómeno de la revolución de las comunicaciones-NTIC's (desde mediados del siglo XX). Aspectos que constituyeron y definieron las actuales características del capitalismo, cuyo poder en esta etapa,

...agudiza el desempleo estructural y se consolidan tanto la financiarización del capital (...) como la hipertecnocratización de la racionalidad instrumental, busca ampliar su dominio y las bases de la acumulación por medio del despojo,

6. Hegel, pensaba acerca de la juventud de América, afirmando que esta se encontraba en el "estadio subjetivo", o incluso, "en el salvajismo donde el ser humano está atado a la naturaleza y es incapaz de razonar" (Quijano Valencia, 2006:68) y menos de construir Estado como sí lo había realizado Europa. 
expandiendo de modo creciente la explotación de la naturaleza, causando desequilibrios irreversibles en los ecosistemas y despojando a los pueblos (...) de sus territorios y sus medios de producción (Marañon-Pimentel, 2014: 21).

Esta amalgama de contextos, se establecerían como resultado, de la construcción de aquella plataforma desde donde se implementó para Latinoamérica, la teoría del desarrollo impulsada por la doctrina Truman (Escobar, 1996). Teoría que ha determinado las modernas relaciones sociales que no sólo atraviesan a la economía, sino que también, se hacen presentes en todas las esferas del acontecer de lo social, como es el caso de la educación.

\section{El desarrollo como modelo contemporáneo del moderno sistema mundial}

El concepto de desarrollo va de la mano del concepto de modernización, que a partir de la finalización de la segunda guerra mundial, ha rondado los paradigmas de administración social de los Estados. El desarrollo sería por tanto, la búsqueda del bienestar y el buen vivir de las personas, mediante el crecimiento económico de las naciones.

Uno de los grandes ganadores de la segunda guerra mundial, Estados Unidos, a través de la exportación de capital y las ideologías de new deal y del buen vecino de los gobiernos de Roosevelt y Truman, creó un modelo de desarrollo económico social, para aplicarlo en un primer momento sobre los países que quedaron destruidos tras la guerra y, en un segundo momento, para emplearlo sobre los países considerados débiles económicamente o de "periferia", como era el caso de los latinoamericanos, dando configuración a aquello que en esta región, se denominó como el "modelo cepalino de desarrollo".

A través de este, Norte América, mediante la Comisión Económica para Latinoamérica -CEPAL-, organizaba la producción de estos países, utilizando como método la industrialización por sustitución de importaciones; así, contralaba la capacidad de endeudamiento de los países latinoamericanos, como resultado de "los imperativos que Estados Unidos enfrentaba al final de la guerra [que] situaron a América Latina y al resto de la periferia en un espacio bien demarcado dentro de la economía capitalista mundial” (Escobar, 1996: 147).

El modelo cepalino de desarrollo para Latinoamérica, causó un estancamiento económico, debido a que partir de su implementación, se produjo un renovado ejercicio de colonialidad del saber y del poder por parte de Norte América. Así, se impone una ideología de dominación, donde el desarrollo, es una estrategia de colonización, a nivel económico y social, evidente en las relaciones unilaterales de comercio, mercado, importación y exportación de capitales.

Pero el modelo cepalino, al igual que las políticas del buen vecino que manejó Estados Unidos, se fue desgastando, puesto que mientras este se aplicó, la deuda latinoamericana se duplicó y triplicó. En estos contextos, el hermetismo de los mercados extranjeros hacia las producciones nacionales, dieron como resultado un Estado protector de la industria nacional, al mismo tiempo que las mercancías y los bienes de capital estadounidenses invadían las economías locales, provocan- 
do que los Estados latinoamericanos, para mantener una competencia equitativa entre la producción local y la producción norteamericana, recurrieran al endeudamiento y como medida adicional, a la devaluación de la moneda. Se produjo así la inflación, que para muchos países más maduros industrialmente en la región, fue hiperinflación.

La devaluación de las monedas locales impulsó al consumo (esto sucedió porque la producción debía rebajar los precios, para que sean más accesibles al consumidor final). Por eso, las sociedades latinoamericanas se volvieron consumistas, lo que agravó las relaciones de colonialidad con el país del norte, (si se piensa, que el modelo de desarrollo no promovió el ahorro interno, ni la inversión tanto nacional como privada, sino que conllevó a un retrasó económico-social de los países Latinos, sobre todo, tras la caída de tal modelo). Estas relaciones de colonialidad consolidadas, fortalecieron no sólo la dependencia, sino la carencia de la construcción de conocimientos propios, favoreciendo la imposición de saberes exógenos.

En los primeros años de la implantación del modelo cepalino sobre los países latinoamericanos, se comenzó a evidenciar una crisis social en el campo, puesto que el método de industrialización por sustitución de importaciones, pretendía impulsar al sector secundario de la economía ${ }^{7}$, dejando al sector primario rezagado, esto en la medida en que las relaciones de colonialidad del saber (imposición de tecnologías y métodos) impedía una explotación efectiva de recursos, situación que se agravaba por las dinámicas de la colonialidad del poder, esto es, la priorización de ayudas estatales a sectores afines con las necesidades impuestas por el modelo.

Es así como se generaron nuevas olas de violencia en el campo, producto del atraso y el olvido del mismo, por parte del Estado. Una consecuencia de tal violencia social, fue en un primer momento la creación de guerrillas, en un segundo momento, el nacimiento de las primeras organizaciones de autodefensas y, en un tercer momento, el fortalecimiento de los ejércitos locales. Los movimientos guerrilleros tomaron importancia tras la revolución cubana, puesto que esta logró una mayor equidad entre los habitantes de dicho país: una repartición equitativa del proteccionismo estatal, acompañado de una reforma agraria de carácter ortodoxo, así como la expropiación de las industrias y bienes de capital extranjero (principalmente norteamericano); situaciones que conllevaron a la internacionalización del conflicto y desde este, a la permeabilización de la guerra fría en la región.

Los movimientos guerrilleros de la región, conllevaron a que Estados Unidos tomara medidas drásticas en pro de no perder su hegemonía, ni las dinámicas de colonialidad del saber y poder que imponía sobre los procesos evolutivos de las economías y las sociedades de Latinoamérica; por ello, ese país propició la represión violenta de los movimientos sociales, así como la imposición de dictaduras de extrema derecha y de gobiernos aliados, logrando así la consolidación del dominio colonial en la región latinoamericana. La reacción norteamericana, provocó en mu-

7. Al respecto Luis Jorge Garay S señala: "Para la Cepal, el crecimiento disparejo entre los países del centro y de la periferia provenía del modelo clásico basado en la división del trabajo, en el cual los países del centro se especializaban en bienes intensivos en capital y los de la periferia en bienes intensivos en mano de obra" (Garay S, s.f.) 
chos países el recrudecimiento de los conflictos internos, sobre todo en aquellos países que no tenían la suficiente madurez industrial capaz de ocupar la oferta laboral local; tal fue el caso de Nicaragua, Guatemala, Perú, México, Honduras, Costa Rica y Colombia ${ }^{8}$ (donde el conflicto no se ha resuelto hasta la contemporaneidad).

Tras el fin de la guerra fría, el mundo viviría a nivel económico un nuevo tipo de desarrollo que se basaría en las leyes económicas liberales de Smith, aplicadas o moldeadas a las condiciones contemporáneas de producción y de relaciones internacionales; a este modelo se le denominaría neoliberalismo.

El neoliberalismo provocó para las economías latinoamericanas, aquello que se conocería como la apertura económica; su lógica era que al introducir un elemento de competitividad extranjera, la calidad de los productos internos y la innovación aumentarían, situación que conllevaría a que los precios de la producción se reduzcan y sean mayormente asequibles para el público en general.

Durante el modelo cepalino, las industrias locales eran las que invadían sus propios mercados, producto del proteccionismo tanto local, como extranjero; esto llevó a que la oferta superase a la demanda, así como a la reducción de la calidad de esa producción. Por eso, y tras el desgaste económico-social, la región latinoamericana en general, decidiría abrir sus fronteras comerciales, pensando que con esto, podrían expandir la oferta de producción y fortalecer la industria local. Pero, al contrario de lo que se esperaba, la apertura económica fortaleció las relaciones de colonialidad del poder, puesto que la apertura de mercado, conllevó a que se manejen las necesidades de los Estados, fuera de sus fronteras; esto, con el fin de imponer productos industriales extranjeros y rediseñar los procesos productivos locales, en otras palabras, limitar la producción local.

No obstante, la apertura económica generó la pérdida de aquella industria local, así como la privatización de instituciones de carácter estatal; aquello, en pro de provocar la inversión privada o extranjera sobre los mercados. De otro lado, la explotación de los recursos minerales y energéticos de estos países, quedaba a la deriva, dirigidos a que cayeran en manos extranjeras; tales condiciones, son resultado de las relaciones coloniales del poder y del saber, puesto que las empresas con más capitales económicos y culturales (conocimientos de técnicas y tecnologías más eficientes) eran las que habían tenido mejores condiciones en su desarrollo, como resultado de un acompañamiento institucional, que por lo general, tenían las empresas foráneas, principalmente las norteamericanas.

Esto generó una reducción de la participación de los Estados, dejando a los habitantes de los mismos, en medio de un panorama mercantilista de oferta y demanda salvaje, dentro del cual, sólo los que se adapten con mayor facilidad, sobrevivirían a las inclemencias de aquella apertura.

8. Luis Alberto Restrepo M. señala: "En Colombia, el Frente Nacional (1958-1974) condujo a una ruptura esquizofrénica entre el "país político" y el "país nacional". En esta brecha prospera el enfrentamiento de guerrillas con fuerzas armadas, y la "guerra sucia" del establecimiento contra las organizaciones populares y la cultura. Si a esto se añade la violencia del narcotráfico y la delincuencia común, podemos decir que el país se encuentra en el ojo ciego del torbellino" (Restrepo M, 1988: 13) 
A nivel inflacionario, la apertura económica generó cambios, puesto que una de las características del modelo cepalino de desarrollo, fue el mantener un tipo de cambio fijo sujeto a las necesidades competitivas del mercado, así como a la importación del capital norteamericano; situación que produjo una devaluación paulatina de las monedas locales, así como la pérdida de poder adquisitivo de las mismas. Con la apertura económica, el tipo de cambio fue flexible; esto quiere decir que las monedas locales dejaron de tener un poder adquisitivo controlado, quedando este, no en manos del Estado, sino en manos de las condiciones de oferta y demanda, devaluación o revaluación, sometidas a las leyes del mercado y de la economía especulativa.

El neoliberalismo conllevó y conlleva a que el mundo se dividiera de acuerdo a las capacidades comerciales y competitivas de los países; el primer mundo, quedaría compuesto por los ocho Estados con mayor poder económico y de producción, entre ellos se encuentran países como: Estados Unidos, Alemania, Francia, Inglaterra, entre otros; el hasta hace poco denominado segundo mundo, estaría constituido por países no alineados como: China -la emergente potencia del primer mundo- y Rusia, países que no dependen económicamente de los países del primer mundo para concebir un modelo de desarrollo; y, los países del "tercer mundo", comprendido por Estados como los latinoamericanos: países completamente dependientes de los países del primer mundo, puesto que necesitan de su capital para desarrollar su poder infraestructural, de sus mercados para poder comerciar la limitada producción y de sus mercancías para poder diversificar los mercados locales, en otras palabras, países que necesitaban ser colonizados, desde las lógicas neoliberales del establecimiento del poder y del saber.

Estos países llamados así: del tercer mundo o en vías de desarrollo, estarían desde estas perspectivas estancados, porque por lo general, habrían sido países que venían de una relación unilateral de dependencia con un país desarrollado o poderoso en términos económicos. Para Latinoamérica, esta dependencia (relaciones de colonialidad del poder y del saber) ha estado sujeta a su relación con Estados Unidos, país auto-constituido como su mayor verdugo económico; mientras que para los países africanos, la Unión Europea fue aquel gigante que moldeo la economía africana a sus necesidades.

El modelo neoliberal, ha sido uno de los mayores factores que ha incrementado la desigualdad social a niveles locales e internacionales, en la medida en que los países del tercer mundo, han tenido que importar mayores cifras de capital, para poder crear mejores condiciones mayormente infraestructurales que facilitarían la entrada de producciones extranjeras, así como la salida de la producción local limitada por condiciones expuestas por los mercados internacionales, esto es, las dinámicas de colonialidad del poder y del saber, que ejercen las potencias económicas sobre sus "neo-colonias".

Para poder convivir dentro del neoliberalismo, los países débiles económicamente, han tenido que crear ciertos mecanismos que den la sensación de supervivencia o consolidación económica; esos mecanismos son las creaciones de comunidades de países vecinos como la Unión Europea, o el Mercosur en el cono sur de Sur 
América; comunidades que buscan la protección de su producción local frente a la fuerte competencia que representa la producción extrajera.

Otro mecanismo de supervivencia en este contexto neoliberal ${ }^{9}$, han sido los tratados de libre comercio entre naciones que representan un mercado confiable, y esta noción de confiabilidad lleva a que las naciones más débiles busquen alianzas con países muy superiores a nivel productivo; un ejemplo de ello es el tratado de libre comercio firmado entre Colombia y Estados Unidos, donde Colombia, pretendió asegurar un mercado para sus productos insignias como es el café y las flores, sometiendo el resto de la producción a una competencia desigual frente a la producción norteamericana, la que en términos de cantidad, supera por mucho a la producción colombiana; así, siguiendo estas las lógicas neoliberales, los tratados de libre comercio reafirman las relaciones coloniales entre países hegemónicos, con países débiles a niveles de producción.

Estos modelos económicos de desarrollo, influyeron en todos los sectores de la vida cotidiana de los países latinoamericanos, siendo el sistema educativo, uno de los sectores a través de los cuales, los mismos tuvieron mayor incidencia. Durante el siglo XIX, hasta la primera mitad del siglo XX (finalización de la segunda guerra mundial) la educación no fue vista como un pilar de desarrollo personal y social; todo lo contrario, las instituciones educativas eran vistas como un elemento que dividía a las sociedades entre ricos y pobres, puesto que los primeros, eran los únicos privilegiados quienes podían ingresar a dichas instituciones, sobre todo los hombres, sin mencionar el hecho que en algunos lugares apartados, se utilizaba a estas instituciones para evangelizar y adoctrinar a las personas.

Pero tras el final de la segunda guerra mundial, el auge de los movimientos civiles y sindicales, conllevaron a la democratización de la educación; en un primer momento, para alfabetizar a los habitantes de los países latinoamericanos y, en un segundo momento, para la creación de mano de obra calificada; esto, en pro de poner en práctica el método de industrialización por sustitución de importaciones del modelo cepalino de desarrollo.

En Latinoamérica, el auge de la educación conllevó a una explosión en las tasas de alfabetización, así como al auge de las ideas de educación universal de la Europa del siglo XIX.

En los años 60, América Latina había experimentado los más elevados índices de crecimiento educacional del mundo. La tasa de alfabetización había crecido entre 1970 y 1990, se seguían incorporando masivamente las mujeres al sistema escolar y la tasa de escolarización primaria estaba evolucionando favorablemente. La represión en la cultura y en la educación pública que ejercieron las dictaduras militares no había alcanzado para interrumpir totalmente el impulso que tenía la educación desde mediados de siglo y luego, durante los primeros años de la normalización constitucional en varios países, se dio un nuevo empuje a la instrucción pública (Puiggrós, s.f.).

9 Aunque sujetos a los procesos coloniales de la colonialidad del poder y del saber. 
Una de las ventajas del fortalecimiento y la popularización de la educación, era la facilidad de crear valores ciudadanos acordes con la construcción de los Estados- nación, y la vinculación de las mujeres al sistema escolar. No obstante, tras los movimientos estudiantiles que surgieron en Francia en mayo del 1968, se comienza a mirar a la educación, particularmente a la educación superior, como un pilar fundamental en la vida cotidiana de los países latinoamericanos. Pese a que se relacionó a los movimientos estudiantiles con el fortalecimiento políticoideológico de las guerrillas, la educación superior fue creciendo.

La educación superior, a pesar que en su gran mayoría y, durante el periodo cepalino era pública, no podía satisfacer la demanda, por lo que en la década de los 80, se comenzó a expandirla hacia las provincias. Sin embargo, donde las dictaduras y las juntas militares gobernaron, se miró a la educación sólo como un elemento doctrinario y, a la educación superior como un elemento subversivo, ya que muchas organizaciones guerrilleras nacieron dentro de las paredes de las facultades latinoamericanas; esto provocó la persecución de estudiantes y docentes, así como la desaparición de los mismos, por parte de las fuerzas oscuras de los Estados.

En los países donde las dictaduras reinaron, la apertura económica llego más temprano que a los países del resto de la región; tal fue el caso de Chile. Tras la apertura económica, el Banco Mundial sugirió al Estado chileno que disminuyera los gastos de la educación pública y promoviera la inversión en educación a capitales privados; así, mientras las instituciones estatales se debilitaban y, se agudizaba la crisis financiera de las mismas, la educación privada se extendía, sin la supervisión del Estado. Esta comercialización de la educación, representó una forma de colonialidad del saber, puesto que esa educación sólo se concentraba en reproducir conocimientos -sobre todo técnicos-y no producir saberes, que ayuden a la consolidación de los sectores productivos impuestos por las relaciones coloniales de poder. Aspecto que disminuía la calidad de esa educación, además que buscaba promover el endeudamiento por parte de la población, si quería entrar en ese sistema educativo.

Mediante la apertura económica, la tasa de alfabetización que se había incrementado en Latinoamérica durante la década de los 60`s y 70`s, comenzó a declinar, puesto que la educación dejo de ser pública y pasó a ser parte del sector terciario de las economías en la región. Uno de estos efectos, fue la promoción y expansión de la educación técnica, descartando la educación profesional, sobre todo, por parte de las instituciones privadas; esto con el fin de crear mano de obra especializada y barata.

A parte de lo anterior, sólo en Colombia, uno de países de la región al que el Banco Mundial le dio la posibilidad de tener una transición de más de 10 años para pasar de su modelo de desarrollo extremadamente cerrado, a un modelo exageradamente abierto para su economía -como lo representaba la apertura-, la deuda del Estado hacia las universidades públicas se había incrementado, mientras tanto este promovía a sus ciudadanos, el sacar créditos educativos a través del Instituto Colombiano de Crédito Educativo y Estudios Técnicos en el Exterior -ICETEX-.

El Icetex, en un principio parecía ser una opción para acceder a una educación superior de calidad, con condiciones crediticias favorables para los usuarios de 
los créditos ofrecidos por el mismo. Pero los usuarios de tales créditos, no estaban preparados para pagar intereses, los cuales con el paso de los años escolares se volverían impagables; incluso sólo en intereses, los usuarios llegaban a deber el 150\% del valor del crédito, aparte del crédito en sí mismo.

\begin{abstract}
La Asociación Colombiana de Usuarios de Préstamos Educativos -ACUPE- es la única organización que se le ha parado de frente al Icetex y ha denunciado los desórdenes administrativos, el sistema de aplicación de tasas de interés, los traslados tardios al cobro y los abusos con los estudiantes y familias que han acudido a sus préstamos para estudios. No han valido las solicitudes de entrevista con el Presidente de la República, ni con la Ministra de Educación, ni los múltiples derechos de petición, ni las tutelas, para lograr que se haga justicia con los cerca de 26 mil estudiantes que deben pagar deudas superiores hasta en un 150 por ciento debido al cálculo de intereses que hace el Icetex, y al caos en la gestión (Morales, 2013).
\end{abstract}

Igualmente, el Estado colombiano por medio del Icetex, ha incrementado su deuda con el Banco Mundial, puesto que se negoció un crédito bajo los estándares de tipo de cambio fijo; esto en pro de poder salir rápida y eficazmente de la deuda por concepto de educación. Pero, dado el contexto de tipo de cambio flexible que tiene el país, lo anterior hizo que esa deuda se multiplicara por no poderse devaluar la moneda y, por el comportamiento de las divisas extranjeras en el mercado especulativo:

La deuda que el Icetex tiene desde 2008 con el Banco Mundial parece no haber sido tan buen negocio como lo quiere hacer ver la entidad. Una estrategia financiera, con la que querían blindar la deuda del vaivén del precio del dólar, resultó ser un remedio más caro que la enfermedad. Hoy, por US\$173 millones que le prestaron entre 2008 y 2010, el Icetex debe pagar \$372 mil millones, en vez de \$307 mil millones al precio actual del dólar. Es decir, casi \$65 mil millones más, sin contar con lo que representa el sobrecosto en intereses (Marín Correa, 2012).

Asimismo, las relaciones de importación de capitales en pro de fortalecer modelos educativos, de carácter privado, obedece a las relaciones de colonialidad, puesto que los beneficiarios de esa educación deben involucrarse rápidamente en los sistemas productivos impuestos, favoreciendo las dinámicas de dominación; además, esa educación no propicia la innovación, tanto en la construcción de nuevos conocimientos, como en la creación de nuevos sectores o factores de producción locales. Más aun, el fomento del crédito educativo transporta esas relaciones coloniales a la continua construcción social y cultural, donde los individuos asumen la responsabilidad de importaciones de capitales extranjeros, igual que la imposición de diseños educativos que se constituyen en herramientas prediseñadas para prolongar el control sobre movimientos sociales que afectan o alteran las relaciones de dominio colonial preexistentes.

Lo anterior, es evidencia de una crisis civilizatoria emergente; crisis evidente en las esferas de la educación y producto de la instauración de modelos de desarrollo pensados desde fuera de los lugares de su implementación o descontextualizados 
a las necesidades de las sociedades latinoamericanas; aquellas, dadas por las dinámicas llevadas a cabo por sus gobiernos de turno y por las imposiciones de las potencias, las cuales han promovido, como el caso arriba citado sobre la educación superior en Colombia, que todos los sectores de la cotidianidad de la existencia social (economía, educación, salud, política, justicia, entre otros,) se encuentren enclaustrados bajo las órdenes del desarrollo económico mundial neoliberal, en el marco del moderno sistema mundial.

\section{Transformar el pensamiento para cambiar el modelo de desarrollo y modificar la educación}

En un documento titulado la cabeza bien puesta, Edgar Morín, manifiesta que si la humanidad no genera un proceso de transformación de las vigentes maneras de pensar, será imposible entender la complejidad del mundo y por lo tanto, descifrar los caminos que posibiliten la superación de la llamada crisis civilizatoria, a través de la educación. Aspecto que debería traducirse para el contexto latinoamericano, como la superación del desarrollo económico, hacia la consolidación de una racionalidad alternativa para la construcción de un modelo alternativo para la continuación de la vida.

Las sociedades occidentales, en los procesos de producción del conocimiento y en los mismos que ha posibilitado el desarrollo del sistema mundo capitalista, han gestado una dinámica de pensamiento en la cual el reduccionismo ${ }^{\mathbf{1 0}}$ y la hiperespecialización ${ }^{11}$ se han convertido en constantes, que no hacen más que fraccionar el mundo y sus cosas, separándolos de la totalidad a la cual pertenecen y por lo tanto eliminando su complejidad y sistematicidad (Morin, 2007: 14). Se trata de un sistema de pensamiento cerrado al entendimiento de lo complejo ${ }^{12}$, en el cual opera una "inteligencia ciega".

... la inteligencia que no sabe hacer otra cosa que separar, rompe lo complejo del mundo en fragmentos disociados, fracciona los problemas, convierte lo multidimensional en unidimensional. (...) Una inteligencia incapaz de encarar el contexto y el complejo global se vuelve ciega, inconsciente e irresponsable. De esta manera los desarrollos disciplinarios de las ciencias no sólo aportaron las ventajas de la división el trabajo, también aportaron los inconvenientes de la superespecialización, del enclaustramiento y de la fragmentación, también produjeron ignorancia y ceguera (2007: 15).

10. En cita de Aurelio Peccei y Daisaku, Morin dice: "El enfoque reduccionista, que consiste en remitirse a una serie de factores para solucionar la totalidad de los problemas planteados por la crisis multiforme que atravesamos actualmente, es menos una solución que un problema” (Morin, 2007: 14).

11. Consiste en "la especialización que se encierra en ella misma sin permitir su integración en una problemática global o en una concepción de conjunto del objeto del que sólo considera un aspecto o una parte"; se trata de fragmentar en parcelas lo total. Impide ver lo global, lo sistémico y disuelve lo esencial (Morin, 2007: 13).

12. Lo complejo, o el pensamiento complejo que involucra el "desafío de la complejidad" consiste en comprender que "existe complejidad cuando no se pueden separar los componentes diferentes que constituyen un todo (como lo económico, lo político, lo sociológico, lo psicológico, lo afectivo, lo mitológico) y cuando existe tejido interdependiente, interactivo e interretroactivo entre las partes y el todo, el todo y las partes" (Morin, 2007: 14). 
La inteligencia ciega, como constante en los procesos de sostenimiento y emergencia del mercado, de los modelos occidentales del desarrollo, o en una palabra de las características del capitalismo-colonial-moderno, no ha hecho más que permitirle al ser humano, la única necesidad de concentrar su pensamiento y dirigirlo hacia la realización y materialización de actividades en una sola dirección, esto es, el reduccionismo o la unidimensionalidad evidente en sus procederes: tal es el caso del mantenimiento de un modelo económico del desarrollo en Latinoamérica, para el que únicamente interesa sostener una dinámica de mercado unilateral, que como arriba quedó señalado, favorece las pretensiones de Estados Unidos o de las potencias mundiales frente a sus ambiciones de acumulación de capital; aspectos que no sólo atraviesan la economía, sino que redundan en todas las esferas de la sociedad, como sucede con la Educación, dado el hecho de la carencia por parte de sus precursores de la necesidad de pensarla holísticamente, complejamente, y no al servicio de la economía de mercado, como lo hace el modelo de desarrollo capitalista. $^{13}$

Ante estas circunstancias, Morin propone que el ser humano debe tener la "cabeza bien puesta"14; hecho que generaría un movimiento de pensamiento necesario que permita librarle de la inteligencia ciega, como condición sine qua non, la materialización de un modelo de desarrollo alternativo o modo de vida alternativo sería imposible.

La cabeza bien puesta, implica una transformación del pensamiento y, la transformación del pensamiento, posibilitará la construcción de unas condiciones mínimas necesarias hacia el establecimiento de un modelo de desarrollo alternativo o un modo de vida alternativo capaz de aprehender en sus particularidades, las especificidades de lo complejo -esto es no sólo lo económico, sino todas las esferas de la vida misma, de la naturaleza, del planeta y del universo que como un sistema se encuentran interconectadas e interrelacionadas y que influyen directa e indirectamente en las características de la existencia humana-; y, capaz de redundar en la construcción y/o modificación de la educación; una educación que lejos de

13. Con relación a ello, no cabe duda que el modelo de educación que desde está dinámica emergió para Latinoamérica se hizo evidente en el proceso que comenzó en Uruguay con las políticas resultantes de aquello que a inicios de la década de los sesenta se llamó como la "Alianza para el progreso", en la cual la educación quedaría desde entonces, sometida a dinámicas curriculares que condujeron a que los procesos de enseñanza-aprendizaje, dados al interior de las aulas de las instituciones educativas latinoamericanas, se concentraran en conducir a los estudiantes y el futuro profesional de los ciudadanos latinoamericanos, por la senda que ratificaría la permanencia del modelo. Se trataba de educar para el desarrollo, aspecto que mediante inversiones ofertadas por el BID (Banco Iberoamericano para el Desarrollo), garantizaría ampliar en el contexto social latinoamericano una fuerza laboral, sirviente de las necesidades del mercado. Más que educar para el beneficio propio latinoamericano, se pretendía educar para dinamizar el mercado y los procesos desarrollistas (Chalapud Velasco, 2000.) De la misma manera Ivan Illich manifiesta: “... los gobiernos americanos constituyeron una "alianza para el progreso"; o tal vez para frenar el progreso, aunque más bien parece una "alianza" al servicio del "progreso" de las clases medias". (Illich, 2006: 100).

14. La condición necesaria para que la cabeza esté bien puesta implica que: "mucho más importante que acumular el saber [situación que coadyuva al reduccionismo y la hiperespecialización] es disponer simultáneamente de: Una aptitud general para plantear y analizar problemas [; y unos] principios organizadores que permitan vincular los saberes y darles sentido" (Morin, 2007: 23). 
corresponder con las exigencias del sistema mundo capitalista, corresponda con la emergente necesidad de superar la crisis civilizatoria, desde los horizontes de la urgente creación de un modo de vida alternativo.

Julián Sabogal, manifiesta que "una propuesta alternativa tiene dos tareas esenciales: crear un pensamiento social alternativo y proponer una nueva concepción de ser humano" (2010:164). El pensamiento social alternativo debe corresponder con lo complejo, mientras la nueva idea de ser humano, debe superar la concepción tradicional del mismo dada por la economía del mercado, desde la cual y en un sentido unidimensional "el valor fundamental que se pone en juego en el modelo imperante, (...) es el egoísmo” (Sabogal, 2010: 164). Se trataría entonces de transformar los valores fundamentales del ser humano que para el caso de una propuesta alternativa "han de ser entre otros: generosidad, solidaridad, libertad, respeto a la diferencia” (Sabogal, 2010: 165). En síntesis,

Ha de ser necesariamente un pensamiento para la comprensión de la complejidad, no solamente porque es la tendencia contemporánea de las ciencias sino porque la multidimensionalidad de los humanos y de las condiciones sociales, en las cuales las dimensiones humanas puedan desplegarse, así lo exigen. Creemos útil también, en esta elaboración, un regreso al significado primigenio del concepto de desarrollo, que, como quedó dicho, era: desdoblamiento de lo que está en germen... de razas, de plantas y de animales. Esta definición da la oportunidad a pensar en las potencialidades internas de las regiones, como puntos de partida hacia el desarrollo (Sabogal, 2010: 171).

Tales puntos de partida hacia el desarrollo, que no tienen que ver con su versión económica y que priorizan para su despliegue la transformación del pensamiento y la construcción de una nueva idea de ser humano, han definido una ruta que desde el trabajo de Julián Sabogal, ha tomado tintes diferentes pasando desde su conceptualización de lo que él denominó como desarrollo humano multidimensional (2010), hasta aquello que actualmente denomina como el modo de vida alternativo (2013).

En cuanto al desarrollo humano multidimensional, el autor afirma que para lograr su consecución, se requiere la sustitución de los interrogantes fundamentales del modelo imperante, que permitirán asumir nuevas posiciones frente a: el ser humano, el cambio en la relación del modelo imperante (desarrollo económico) frente al ser humano, un cambio del objeto de la economía (uno pensado al servicio de la humanidad), el cambio en el mecanismo del funcionamiento del modelo y la final transformación del modelo. Situaciones plausibles, si se comprende y se lleva a la práctica el hecho de aceptar que:

Las dimensiones del ser humano son múltiples: (...) es un ser biológico, es un ser natural, es un ser social, es un ser político, es un ser afectivo, es un ser inteligente, es un ser lúdico, es un ser trascendente. Se sobreentiende que las dimensiones están interrelacionadas en forma sistémica, no se trata de partes separadas o separables, sino de un todo complejo (Sabogal, 2010: 183).

Esta interrelación, esta multidimensionalidad del ser humano, desborda la unidimensionalidad del modelo de desarrollo económico, pensado para el servicio 
de la economía. Así las cosas, el desarrollo humano multidimensional, serviría a todas las dimensiones de lo humano, lo social y lo complejo y no sólo a una, como sucede con el modelo imperante al servicio del mercado y del capital. Por eso,

A diferencia del modelo imperante, que sólo entiende a los humanos en cuanto compradores, lo que Marcuse llamó el hombre unidimensional, proponemos rescatar en el modelo la multidimensionalidad del ser humano. El ser humano, entonces, es multidimensional y cada una de sus dimensiones es una potencialidad. El modelo no tiene fin de satisfacer, sino de proporcionar las condiciones para que los humanos pongan en juego sus potencialidades (Sabogal, 2010: 10).

Esta perspectiva de desarrollo humano multidimensional, como la prioridad de proporcionar los medios para que los individuos dispongan libremente de sus potencialidades, se complementa y se traduce -si se sugiere el hecho del ejercicio de re-significación que Sabogal realizó frente a sus propias categorías-, en el modo de vida alternativo, del que manifiesta lo siguiente:

Hablamos de modo de vida y no de modelo de desarrollo, porque no estamos pensando en la necesidad de producir bienes y servicios por sí mismos (...); tenemos como preocupación principal la vida concreta de los seres humanos. La condición sine qua non para cualquier actividad humana, sea esta del cuerpo o de la mente, es estar vivo. Garantizada la vida, hay que pensar en las condiciones de esa vida, y en ese sentido estamos pensando en colectividades humanas en condiciones de bienvivir. (...) Hablamos de las condiciones mínimas para garantizar la vida, después de contar con estas, de estar vivos, vienen las otras condiciones del bienestar y aquí empieza a jugar un papel importante la libertad para escoger alternativas, no se pueden elegir alternativas sino estando vivo, pero no debemos detenernos en las garantías de la dimensión biológica del ser humano, la vida tiene sentido como una condición indispensable para la búsqueda del bienvivir (Sabogal, 2013: 59).

Sería la búsqueda del bienvivir ${ }^{15}$ por parte de la misma humanidad, desde la conciencia de sus cualidades multidimensionales, la que conduciría a la gestación de un modo de vida alternativo al modelo imperante; modo de vida en el cual ineludiblemente la educación debe contemplarse.

Esta educación, pensada cotidianamente, podría aludir a aquel proceso que solamente deben protagonizar las instituciones creadas por el Estado para tal empresa, donde un grupo de personas tenidas en la sociedad como sus profesionales,

15. “...el bienvivir, al menos en la mayor parte de sus componentes, no es un asunto individual sino colectivo. ¿De dónde nace la idea de que el bienvivir es individual? En primer lugar, de la concepción epistemológica que conlleva el pensamiento económico ortodoxo; tal pensamiento tiene sustento teórico atomístico. Es por eso que siempre se tiende a analizar los problemas sociales a partir de los individuos, es el modelo del Robinson Crusoe. Nosotros no compartimos ese camino de análisis, porque partimos del principio según el cual el ser humano es un ser social, el ser humano solo es tal en sus relaciones con sus semejantes, el individuo al margen de la sociedad simplemente no existe" (Sabogal, 2010: 221). 
son los encargados de ejecutar procedimientos educativos, con personas en edad de ser educadas y/o carentes de educación, quienes mediante la operación, habrán de obtener las herramientas necesarias que además de socializarles -peor o mejor "adecuarlos" para la vida en sociedad- permitirán generarles una expectativa de existencia, que les brinde un cierto grado de autonomía y "buen vivir"16.

Sin embargo, si entendemos la raíz etimológica del término surgida del latín educere, que significa "guiar, conducir" o educare, que se interpreta como "formar e instruir” y, si consideramos todavía las diversas conceptualizaciones que se han producido respecto del tema, el asunto se torna complejo; más aún, si la discusión trasciende del qué es la educación como parte del modelo imperante, al qué debería ser la educación como inmanencia de una racionalidad y un modo de vida alternativo. Aspectos que sin duda, se circunscriben al lugar, al contexto, o a la plataforma (modelo) desde donde se los piensa.

Emile Durkheim (1976), por ejemplo, estaba absolutamente convencido que para tratar el tema de la educación, era definitivamente conveniente, visualizarla desde aquello que evidentemente es o se muestra en la realidad, despojándola de cualquier elemento de abstracción que procure percibirla desde un "podría ser" (Usátegui, 2003:180). Y es que Durkheim, analizando a la sociedad industrial progresista de su época, manifestaba que la educación es una práctica social que circunscribe a los individuos, mediante procesos de homogeneización, en una cultura común; despojándoles de su individualidad y estableciendo diferencias de clase entre los mismos, las que, por intereses de las instituciones creadoras de educación, terminaban implantando una suerte de desigualdad social (Usátegui, 2003: 175).

...un sistema educacional no tiene nada de real por sí mismo. No se halla en él sino un conjunto de prácticas e instituciones (...) que son solidarias de las demás instituciones sociales y que las expresan, que por consiguiente no pueden ser cambiadas a capricho, como tampoco lo puede ser la estructura misma de la sociedad (Durkheim, 1976: 92).

De otro lado, y contraria a la interpretación del legendario sociólogo, Kant, planteaba que lejos de coadyuvar a la reproducción y conservación de la cultura, mediante procesos de transmisión del conocimiento como lo es la enseñanza, la educación tendría que solventar y darle concreción a los intereses e ideales humanos pre-existentes, con miras a construir el porvenir de la humanidad. Dice Kant al respecto: "no habrá que educar a los niños, a partir del estado presente de la especie humana, sino de cara a su estado futuro, tratándolo de mejorarlo, es decir, conforme a la idea de la humanidad y a su destino total” (Kant, 1993: 79).

16. A diferencia del bienvivir, el buen vivir como la pretensión única de la educación pensada desde los modelos de desarrollo capitalista, busca generar en los sujetos objeto de procesos educativos, una suerte de pensamiento concatenado con las intenciones del sistema, en la medida de condicionar su vida como una práctica convergente con las particularidades del crecimiento económico, el consumo y la acumulación del capital propias de la existencia de un mercado que garantiza su continuidad; así, un sujeto educado tendrá irremediablemente como condición de vida, aportar desde su existencia y su existencia, hacia las exigencias que plantean los modelos de desarrollo capitalista. 
Es notorio que una y otra perspectiva sobre educación, plantean posiciones que fueron trascendentales y correspondientes a los procesos derivados del sistema mundo capitalista; pero muestran también matices un tanto disímiles, si se comprende la naturaleza, las perspectivas, el objeto y el por qué de sus definiciones, además del lugar de alocución de las mismas (bien en un sentido académico, a decir de la perspectiva sociológica de Durkhein o la perspectiva filosófica de Kant, o bien en un sentido contextual, a decir del momento y el escenario histórico desde donde estos autores han hablado).

De ahí que se hace necesario referir, una suerte de respuesta a la inquietud respecto de quién o quienes, hablan, dicen y hacen la educación -sobre todo en el marco del contexto de las exigencias del modelo imperante-; esto, a partir de la contemplación de la alteridad en educación, esto es, de la relación entre quienes piensan la educación y entre quienes la ejecutan y recepcionan, con miras a pensarla desde la posibilidad de su coexistencia al interior de un modo de vida alternativo, al modelo económico vigente.

Tomemos el ejemplo de la escritura de Paulo Freire, quien por las características de su producción pedagógica, refiere situaciones concretas que permiten visibilizar en educación, la relación entre quienes la producen y respecto de quienes serían susceptibles de una suerte de "beneficio" dado por la misma. Según Freire, "nadie educa a nadie, y nadie se educa a sí mismo. El mundo se educa mediatizado por la sociedad o el mundo" (Freire, 2007: 17). Esta situación permite contemplar, que el esfuerzo educativo trasciende de las posibilidades de decisión que pudiera tomar sobre su educación, aquel o aquellos, quienes quisieran educarse y, se concentra en la reproducción de una práctica social cuyo propósito consiste en satisfacer las necesidades de quienes "conduzcan" -ya desde la legalidad y las particularidades de la formación económica social de su sociedad, ya desde la autoridad, ya desde la tenencia del poder (léase político o económico y entiéndase a la medida de la colonialidad)- un proyecto específico para su sociedad.

Un caso concreto al respecto, habría sido planteado por allá en la década de los ochenta, por Estanislao Zuleta, cuando pensaba la educación en nuestro país para la época, al servicio del desarrollo económico.

La eficacia de la educación para preparar los futuros obreros, contabilistas, ingenieros, médicos o administradores, se mide por las habilidades que el individuo adquiera para realizar tareas, funciones u oficios dentro de un aparato burocrático o productivo. Su eficacia depende también del dominio de determinadas técnicas, poco importa que la realización de las tareas productivas coincida con los proyectos o expectativas del hombre que las realiza. Se trata en esencia de prepararlo como un empleado del capital, por lo tanto, no es muy importante que piense o que no piense los procesos productivos del saber, sino que haya logrado manejar determinadas habilidades que permitan producir resultados determinados (Zuleta, s.f.).

Estas lecturas sugieren que no hay acción del que decide educarse, sobre el objeto de su educación. Por el contrario, es una suerte de estructura, generalmente enclaustrada sobre las traviesas de un proyecto educativo para la sociedad que la 
sustenta, la que decide sobre cómo educar a los individuos de su organización (sociedad). Y es que esto, se vuelve evidente, si se contempla por ejemplo las características del modelo profesionalizante y vigente en nuestro país, que contempla la educación superior ${ }^{17}$.

De ahí que, sin el ánimo de definir, aquello que desde esta escritura pudiera considerarse como una educación alternativa a la impuesta por el modelo económico desarrollista y, lejos aún de afirmar cómo permitir que en educación, exista una suerte de horizontalidad entre los protagonistas del proceso -léase: estudiantes, profesores y sistema educativo (Estado)-, que permita la participación de quienes reciben y se benefician de la educación, es preciso dejar como incertidumbre un intento de cuestionamiento que, en últimas, podría considerarse como la posible conclusión de este esfuerzo: ¿es viable que en nuestros sistemas educativos, desde los currículos y planes de estudio en las diversas áreas del saber, al interior de las instituciones, la educación sea pensada para un encuentro con los otros y el otro? ¿Acaso un desarrollo alternativo o una contribución hacia una racionalidad alternativa anticolonial para la creación de un modo de vida alternativo en la educación, no constituiría una transformación de las relaciones de alteridad entre sus actores?

Por el momento, Julián Sabogal, pensando en la dinámica de la relación enseñanza-aprendizaje y docente-estudiante, afirma que una alternativa para desarrollar la educación desde la educación y, contemplando las potencialidades de sus actores o cada una de sus dimensiones frente a un modo de vida alternativo, se encuentra en el trabajo que deben realizar los docentes, si atendemos a que ellos, como cultores del pensamiento y abanderados por promover la transformación de la realidad social, son responsables desde su eticidad -esto es desde su acción ética y praxis de la alteridad- de gestar acciones concretas para el cambio que saque a la sociedad contemporánea de la “crisis sistémica” que enfrenta.

Digamos, en gracia de discusión, que hay dos maneras fundamentales de hacer docencia, que vamos a llamar el círculo virtuoso y el círculo vicioso. El círculo

17. El modelo de educación superior que rige a nuestro país, si bien se circunscribe a las características normativas que contempla la ley 30 de 1992 próxima a reformarse, se preocupa por atender a las expectativas y exigencias del capitalismo mundial, en el marco del mercado y de la posibilidad de contribuir a la generación de recursos humanos conforme a la oferta laboral existente en dicho mercado; en esa medida, este modelo es auténticamente profesionalizante, puesto que se preocupa por reproducir saberes para el empleo, lejos de producir conocimiento y pensamiento para la preservación de la vida y el trabajo para la vida. Basta con contemplar las políticas del Ministerio de educación Nacional (MEN), subordinadas a las políticas y demandas de organizaciones supranacionales como la OCDE (Organización para la Cooperación y el Desarrollo Económico) y el Banco Mundial, para corroborar dichas situaciones. Ejemplo de ello, son aquellas políticas que hablan entre otros aspectos, principalmente de: pertinencia (esto es educar conforme a las necesidades económicas de las regiones con relación al mercado) y calidad (que entre otras cosas se mide bajo estándares internacionales desde donde se manifiesta si la educación en nuestro país y en diversos países del mundo es de calidad o no, de acuerdo a los resultados de pruebas externas como las Pisa, que evalúan la eficacia y eficiencia de los sistemas educativos, respecto de aquello que se debe o debería enseñar en cada país). No en vano, en el año 2012 la OCDE y el Banco Mundial, manifestaban los siguiente: "El Ministerio de Educación Nacional debe seguir centrándose principalmente en (...) la mejora del aseguramiento de la calidad de la educación superior (tanto en lo relativo al aprendizaje como a la pertinencia) (OCDE \& Banco Mundial, 2012:84). 
virtuoso consiste en las siguientes actividades continuas e interrelacionadas: leer-pensar-escribir-dialogar-leer... y el círculo vicioso: oír-memorizar-repetirolvidar (Sabogal, 2009: 11).

La operación pensada por Sabogal, como actividad propia de un docente, involucra desde sus dos cualidades, dos instancias donde es posible identificar y no identificar una praxis de la alteridad. La primera, la del círculo virtuoso, es aquella donde la alteridad emerge, en tanto que la segunda, es un ejercicio que debe desterrarse y que no considera la alteridad, si no que corrobora la ejecución de "intereses objetivos" poniendo en evidencia la "unidimensionalidad" humana a su servicio; intereses particulares y profesionalizantes, como los que sustentan los currículos pensados por y hacia el desarrollo económico.

El círculo virtuoso del docente, es de por sí, una práctica que puede coadyuvar a la transformación de la realidad social, puesto que ofrece la escenificación de elementos fundamentales para el acercamiento al conocimiento de la realidad social concreta; a decir del ejercicio "leer-pensar-escribir-dialogar-leer".

Dicho ejercicio, involucra el hecho de que el docente se asume desde su papel como docente, concatenándolo con su papel como ser humano multidimensional, consciente de sus posibilidades y potencialidades y, coherente con sus obligaciones y responsabilidades frente a la sociedad en general y respecto de sus estudiantes y la educación en particular. Por tanto, "leer-pensar-escribir-dialogar-leer" como operación y práctica concreta de vida y para la vida del docente, entendido así como "multidimensional", implica la puesta en escena de actos cotidianos que redundarían en resultados favorables a los propósitos de la materialización de prácticas educativas concernientes a la formación y educación de los estudiantes ${ }^{\mathbf{1 8}}$.

Situaciones favorables para la construcción del modo de vida alternativo. Y circunstancias que solventan la ejecución de unas posturas éticas y políticas, pues en ello, el docente como actor de la alteridad, le entregaría a sus estudiantes respeto por su otredad, si se atiende a que en la dinámica, el docente piensa, escribe y dialoga con el Otro, para el Otro y sobre el Otro y lo otro (entendido como la realidad circundante o que le es ajena). Hechos que no pueden realizarse sin aquella existencia y presencia del Otro; esto es del estudiante y de los actores de la sociedad.

18. Entre estos actos como producto de una praxis conjunta, leer implica aprehender y empoderarse del conocimiento y los saberes objeto del ejercicio que convoca la práctica de la docencia; pensar, equivale a procesar mentalmente y plasmar escrituralmente los resultados del ejercicio de leer, esto es de la lectura, a través de productos de escritura, del escribir, que implican la recreación y reproducción del conocimiento, en la medida en que constituyen el aporte propio a dicho conocimiento realizado por el docente. Esto, indudablemente, le permitiría mantenerse al tanto de los acontecimientos de la realidad o de su realidad inmediata, para recrearla, en tanto que sus aportes pasan a ser dialogados - esto es dialogar- y leídos -esto es el leer ya no como al comienzo del proceso, sino como su resultado, puesto que lo que se lee son sus productos de escritura- lo cual, equivale al hecho de ser compartidos a sus estudiantes, coadyuvando y contribuyendo íntegramente con su formación y educación. De ahí que, el docente "multidimensional" es "multidimensional" y virtuoso, en la medida en que se preocupa y se responsabiliza desde sus obligaciones y con sus potencialidades o dimensiones concretas: lectura, pensamiento, escritura, diálogo y lectura, frente al Otro, frente a sus estudiantes y frente a la sociedad. Sólo así, deja de lado todo atisbo de unidimensionalidad, aportando a la transformación de la realidad social. 
En tanto, al círculo vicioso, sólo le interesa salir de paso. El ejercicio oírmemorizar-repetir-olvidar ${ }^{\mathbf{1 9}}$, sería un esfuerzo ensimismado, que ignora al Otro y lo otro, pues se conforma con priorizar un interés particular que, sin indagar por las identidades del Otro y las características de lo otro, jamás podría adentrarse en la construcción de un pensamiento que coadyuve con la transformación de la realidad social. Esto, si se atiende a que tal operación, no contempla el ejercicio de una actividad humana tan necesaria, tan ética y tan pertinente a los intereses mismos de la humanidad, como es el pensamiento - que va más allá de la memorización-; aquel, dirigido a la continua transformación y revolución de las diversas realidades sociales. Realidades que deben ser conocidas en sus esencias a fin de buscar y procurar su transformación.

Son estas realidades, las que deben ser aprehendidas por el Otro, por el estudiante y por el cultor de un pensamiento anticolonial. Así, el estudiante, quien también debe contribuir a la crítica anticolonial desde la construcción de una racionalidad alternativa desde sus procesos educativos, como dinámica para la creación de un modo de vida alternativo, también debe generar alteridad con el Otro y lo otro; tal alteridad, desde la asimilación de su responsabilidad respecto de su educación, debe corresponderse con el círculo virtuoso que debe asumir el docente, puesto que el estudiante al pretender captar la esencia de la realidad social, no puede conformarse simplemente con oír-memorizar-repetir-olvidar (aquello que reproduce la educación tradicional poscolonial), sino que también debe buscar "leer-pensar-escribir-dialogar-leer", constituyéndose de ese modo, ya no como estudiante al margen del sistema -"unidimensional”, que estudia por estudiar ${ }^{20}$ - sino emergiendo como estudiante "multidimensional", con las mismas cualidades y facultades del docente "multidimensionalidad".

19. Tal ejercicio, no es más que la puesta en práctica de un conjunto de conductas que favorecen intereses concretos, pertenecientes al sistema económico capitalista y a los propios de un docente ensimismado y "unidimensional", como actor que actúa siguiendo las consideraciones del sistema. Así, memorizar, no sería más que utilizar los saberes y conocimientos por parte del docente y objeto de su docencia, con el fin de salir de paso; en este sentido, tras cada una de sus clases, el docente se conforma con leer lo necesario para memorizarlo, o grabarlo temporalmente en su mente, y utilizar la información resultante sólo para el propósito específico de su uso, que es transmitirla a sus estudiantes durante la clase. Esta transmisión implica la segunda conducta que sería repetir, la cual equivale a transmitir, o recitar la información memorizada a los estudiantes de su clase. Finalmente, el círculo se completa, con la conducta de olvidar, cuando finalmente, el docente desecha de su mente la información utilizada y transmitida en clases, puesto que no le resulta útil a sus intereses. De ahí que son los intereses, en el sentido del ensimismamiento y la unidimensionalidad del docente practicante de este círculo y que equivaldrían a intereses meramente económicos -se ejerce la docencia sólo por el salario- los que determinarían la praxis cotidiana del docente "unidimensional"; aquel que por sus condiciones, no puede aportar con la transformación de la realidad social constitutiva a la crisis sistémica.

20. El estudiante que estudia por estudiar, el ensimismado, el "unidimensional”, no es más que aquel que, tal como el docente "unidimensional”, actúa bajo las consideraciones del interés del sistema económico capitalista y de los suyos propios. Así, este estudiante también memoriza: cuando aquello que debe estudiar cotidianamente para la aprobación de las diversas pruebas de que es objeto, es aplicado como mera información que se usa para superar la prueba y nada más; cuando repite la información que le es transmitida en clases y no piensa alrededor de la misma y, cuando olvida todo cuanto aprendió porque simplemente no lo necesita, o no sabe como potencializarlo en su uso, esto es el uso de lo aprendido, que no deja de ser desde esta dinámica, simplemente memorizado, repetido y olvidado. 
Luego, tanto el estudiante "multidimensional", como el docente "multidimensional”, a partir de sus esfuerzos desde el círculo virtuoso -como apertura anticolonial para la producción de nuevos saberes y conocimientos, hacia la descolonización del pensamiento que viabilice la construcción de una educación constitutiva al detrimento de la crisis civilizatoria y, a la creación de otra forma de vida alternativa- serán actores fundamentales, en aquel proceso conducente, hacia la superación de la crisis sin precedentes.

\section{Conclusiones}

La crisis civilizatoria como resultado de las dinámicas del capitalismo mundial, debe ser objeto de preocupación por parte de la humanidad. La humanidad debe gestar nuevas formas de pensamiento que le hagan frente y la educación debe jugar un papel fundamental para la materialización de dicho cometido.

Sólo un cambio de pensamiento emergente, capaz de hacer una profunda reflexión respecto de las características constituyentes a la modernidad, como aquel proceso que configuró las cualidades del sistema mundo capitalista, podrá dar las bases que orientará la superación de la crisis civilizatoria. Dinámica que debe contemplar las cualidades del desarrollo como elemento fundamental y transversal a las condiciones del capitalismo contemporáneo y, dinámica que debe dar cuenta del papel que en el proceso debe jugar la educación, entendida como una educación para la superación de la crisis civilizatoria y para la gestación de un modelo de desarrollo o forma de vida alternativa al capitalismo.

La educación entonces, debe ser constituida como un arma que propicie la liberación de los sistemas sociales, esto es, autonomía en los procesos productivos y la organización y construcción de modelos endógenos alternativos al desarrollo, teniendo en cuenta las necesidades locales, tanto para la vida, como de producción y consumo. La educación formaría así, uno de los pilares estructurales para la consolidación económico-social de los Estados, que como se ha hecho referencia, han estado bajo el yugo de necesidades impuestas por mercados, en otras palabras, necesidades impuestas por países perpetradores de los procesos de colonialidad (del poder y del saber).

Esta gestación, debe comenzar con la transformación de las relaciones sociales (de alteridad) que tienen los actores de la educación; así, tanto profesores como estudiantes -y si se quiere la comunidad educativa en general- deben jugar un rol protagónico en los procesos educativos, toda vez que transformen las relaciones de alteridad que se producen en los contextos del aula, a raíz de la puesta en escena del círculo virtuoso. De ese modo, estudiantes y docentes, como actores "multidimensionales", coadyuvarán a la posibilidad de dejar de replicar modelos educativos auténticamente profesionalizantes y se concentrarán con construir pensamiento desde la dinámica de producir conocimiento dada la puesta en escena de la operación: “leer-pensar-escribir-dialogar-leer”, más allá de la ya tradicional práctica del círculo vicioso de la educación, que solamente contribuye a reproducir y dar continuidad histórica a los modelos educativos planteados desde el sistema imperante. 


\section{Referencias}

1. CASTRO-GÓMEZ, Santiago (2005). La poscolonialidad explicada a los niños. Jigra de Letras 5. Editorial Universidad del Cauca, Instituto Pensar, Pontificia Universidad Javeriana, Popayán.

2. CASTRO-GÓMEZ, Santiago; GROSFOGUEL, Ramón (2007). El giro decolonial: reflexiones para una diversidad epistémica más allá del capitalismo global. Siglo del Hombre Editores. Bogotá.

3. CHALAPUD VELASCO, Juan Ramón (2000). Educación, reproducción, resistencia y transformación. Graficolor. San Juan de Pasto.

4. DURKHEIM, Emilio (1976). La educación como socialización. Ediciones Sígueme. Salamanca.

5. DUSSEL, Enrique (2000). Europa, modernidad y eurocentrismo. Universidad Autónoma Metropolitana Iztapalapa (UAM-I), México. En: LANDER, Edgardo. (Compilador). "La Colonialidad del Saber: Eurocentrismo y Ciencias Sociales. Perspectivas latinoamericanas". Gráficas y Servicios, Consejo Latinoamericano de Ciencias Sociales -CLACSO-. Buenos Aires, Argentina.

6. ESCOBAR, Arturo (1996). La invención del tercer mundo: construcción y deconstrucción del desarrollo. Traducción de Diana Ochoa. Editorial Norma. Bogotá.

7. FREIRE, Paulo (2007). La educación como práctica de la libertad. Siglo XXI. México.

8. GARAY S., Luis Jorge (s.f.). De la sustitución de importaciones a la apertura 1967-1996. Biblioteca virtual Banco de la República [En línea] Bogotá. Disponible en: http://www.banrepcultural.org/blaavirtual/ economia/industrilatina/003.htm (Consultado Feb. 4 de 2014).

9. KANT, Immanuel (1993). Reflexiones sobre la educación. Librairie pPhilosophique J. Vrin. París.

10. ILLICH, Iván (2006). Obras Reunidas. Fondo de Cultura Económica. España.

11. MARIN CORREA, Alexander (2012). El mal negocio del Icetex [En línea] Disponible en: http://www. elespectador.com/impreso/temadeldia/articulo-350769-el-mal-negocio-del-icetex (Consultado Feb. 8 de 2014)

12. MARAÑÓN-PIMENTEL, Boris (2014). Crisis global y descolonialidad del poder: La emergencia de una racionalidad liberadora y solidaria. En: MARAÑÓN-PIMENTEL, Boris. (2014). Buen viviry descolonialidad: crítica al desarrollo y racionalidad instrumentales. UNAM, Instituto de Investigaciones Económicas. México. Primera edición.

13. MIGNOLO, Walter (2000). La colonialidad a lo largo y a lo ancho: el hemisferio occidental en el horizonte colonial de la modernidad. En: LANDER, Edgardo (Compilador). La colonialidad del saber: Eurocentrismo y Ciencias Sociales perspectivas latinoamericanas. Gráficas y Servicios, Clacso. Buenos Aires.

14. MIGNOLO, Walter (2002). Las geopolíticas del conocimiento y la colonialidad del poder. En: WALSH, C. SHIWY, F. CASTRO-GÓMEZ S. (Compiladores). "Indisciplinar las Ciencias Sociales. Geopolíticas del conocimiento y colonialidad del poder. Perspectivas desde lo andino". UASB/Abya Yala, en prensa.

15. MORALES, Claudia (2013). Las deudas con el Icetex en ocasiones se triplican [En línea] Disponible en: http://www.semana.com/nacion/articulo/icetex-entrevista-claudia-morales/361919-3 (Consultado Feb. 5 de 2014). 
16. MORIN, Edgar (2007). La cabeza bien puesta. Bases para una reforma educativa. Nueva Visión. Buenos Aires.

17. OCDE \& El Banco Mundial (2012). "La educación superior en Colombia 2012". Serie: Evaluaciones de políticas nacionales de educación. [En línea] Disponible en: http://www.mineducacion.gov.co/ cvn/1665/articles-317375_recurso_1.pdf (Consultado abril, 5 de 2014).

18. PUIGGRÓS, Adriana. Educación y sociedad en América Latina de fin de siglo: del liberalismo al neoliberalismo pedagógico [En línea] Disponible en: http://www1.tau.ac.il/eial/index.php?option=com_co ntent\&task=view\&id=598\&ltemid=236 (Consultado Feb. 5 de 2014).

19. QUIJANO, Aníbal (2000). Colonialidad del poder, eurocentrismo y América Latina. En: LANDER, Edgardo (Compilador). "La colonialidad del saber: Eurocentrismo y Ciencias Sociales perspectivas latinoamericanas". Gráficas y Servicios, Clacso. Buenos Aires.

20. QUIJANO VALENCIA, Olver (2006) ¿Recorre la civilización el mismo camino del sol? Crítica poscolonial, racismo e insurgencia epistémico-existencial. En: ALVAREZ, L. ARISTIZABAL, M. (Compiladores). "¿Recorre la civilización el mismo camino del sol? Pedagogía, subjetividad y cultura". Fondo editorial Universidad del Cauca. Popayán.

21. RAUBER, Isabel (2011). Dos pasos adelante, uno atrás. Lógicas de superación de la civilización regida por el capital. Ediciones desde abajo. Bogotá.

22. RESTREPO M., Luis Alberto (1988). Colombia: resuenan los tambores de mucha guerra, en: "Nueva Sociedad"; ISSN 0251-3552, N 96. Caracas.

23. SABOGAL TAMAYO, Julián (2009). La reforma universitaria un sueño de futuro. Centro de Publicaciones Universidad de Nariño. San Juan Pasto [En línea]. Disponible en: http://reforma.udenar.edu.co/archivo/ documentos/dialogos/la_reforma_universitaria_un_sueno_de_futuro.pdf (Consultado agosto 21 de 2013).

24. SABOGAL TAMAYO, Julián (2010). Desarrollo humano multidimensional. Editorial Universitaria Universidad Nariño. San Juan de Pasto.

25. SABOGAL TAMAYO, Julián (2012). Otro método para comprender la realidad social y buscar su transformación. El pensamiento de Carlos Marx. En: Revista Historia de la Educación Colombiana. Universidad de Nariño: Doctorado en Ciencias de la Educación. Vol. 15. No. 15.

26. SABOGAL TAMAYO, Julián \& Otros (2013). Hacia un modo de vida alternativo. Ediciones Universidad Simón Bolívar. Barranquilla.

27. USÁTEGUI, Elisa (2003). La educación en Durkheim: ¿socialización versus conflicto? En: Revista Complutense de Educación, Vol. 14, No. 1.

28. WALLERSTEIN, Immanuel (1995). La estructura interestatal del sistema-mundo moderno. En: Secuencia Nueva Época, No. 32, mayo-agosto, p. 143-166.

29. WALLERSTEIN, Immanuel (2005). El moderno sistema mundial. Siglo XXI Editores. México.

30. ZULETA, Estanislao. La educación un campo de combate [En línea] Disponible en: http://catedraestanislao.univalle.edu.co/Entrevista.pdf (Consultado Feb. 14 de 2014). 